\title{
Optimal Design of Equivalent Linear Induction Motor Based on Taguchi Algorithm and Analysis Using Finite Element Method
}

\author{
Ch.V.N.Raja ${ }^{1}$ and K. Rama Sudha ${ }^{2}$ \\ ${ }^{1}$ Research Scholar, Dept. Of EE, AUCE, Andhra Uniersity, Andhra Pradesh, India \\ ${ }^{2}$ Professor, Dept. Of EE, AUCE, Andhra Uniersity, Andhra Pradesh, India
}

\begin{abstract}
Linear Induction motors (LIM) are widely used in industrial applications, especially in linear motion locomotive systems. These applications require high efficiency with good power factor. Mostly LIM suffer from low power factor and less efficiency. Due to this energy consumption is high and also it draws more input current. In this paper, a novel multi objective Taguchi algorithm (TA) is proposed to meet required efficiency and power factor in the design of a Linear Induction Motor. Hence, LIM dimensions can then be optimized by using a TA in an appropriate objective functions. 2D Finite Element Method is adopted to analyze the flux density in LIM with the parameters obtained using TA. From the results it is observed that the proposed algorithm outperforms the Genetic algorithm (GA) and Particle swarm optimization (PSO) with respect to the power factor and efficiency.
\end{abstract}

Keywords: Linear Induction motor, dynamical model, Taguchi Algorithm, FEM analysis.

\section{Introduction}

Linear Induction motor is a special conventional rotary motor that is in use to achieve rectilinear motion rather than rotational motion. Linear Induction Motors are usually preferred for achieving linear propulsion in variety of applications due to easy maintenance, high acceleration or deceleration and produce a direct thrust without any conversion of energy. This increases efficiency, the useful life of the system and reduces maintenance costs [1]. Dr. Luciano Martins Neto [2] developed a linear induction motor phase parameter through the process of obtaining voltage and currents at the machine terminals experimentally using determination method. K. Davey [3] proposed Pulsed linear induction motors in Maglev applications to eliminate low power factor, power transfer, smaller end winding overhang, and simpler electronics.

Hofmann [4] investigated applications of a linear induction machine in railways with different coil and slot geometries. Due to noncontact operation and quick response a LIM employed experimentally in steel making plant, electromagnetic force applications to obtain high quality and high productivity in Fujisaki [5]. J.R. Wells [6] presented a linear induction motor design and mount system that are suitable for integration into an educational laboratory. Junha Kim [7] developed constrained optimization technique to reduce the attractive force and power loss strategy in a LIM for personal rapid transit (PRT) systems. H. Amirkhani [8] proposed PC based thrust estimating algorithm for LIM to control thrust, flux and also to eliminate the system from the speed measuring equipment. Haruo Noma [9] designed a digital Proactive desk with Haptic feedback to improve performance of single sided LIM and also to generate a force of more than $10 \mathrm{~N}$ in any direction. T.C.O. Connell [10] re-explores first-principles LIM design by implementing continuum electromechanical models.

Jianqiang Liu [11] developed loss minimize control algorithm to reduce the total copper and iron losses in variable speed and/or thrust force LIM drive by considering the end effect and attraction force. Renato Crivellari [12] discussed influence of End Effect on design parameters of Linear Induction Motor. Nilanjan Chakraborty [13] proposed dual interior point algorithm (IPA) to solve exact distance computation between convex linearly translating objects. V.P. Sakthivel, et [14] suggested multi objective PSO technique to estimate the steady-state

Received: May 4th, 2017. Accepted: September 30th, 2017 
equivalent circuit parameters from the IM performance characteristics. Ai-min Liu [15] established the mathematical model of multi-objective PSO algorithm based on the grain of subgroup algorithm. A. Shri [16] introduced genetic algorithm (GA) to maximize efficiency, power factor and also to reduce primary weight and end effect braking force for a LIM.

Victor G. Lopez [17] developed a discrete-time inverse optimal control to a three-phase LIM in order to meet required tracking position and also PSO is employed to improve identification and control performance. Hamid Yaghoubi [18] explained the importance of maglev transportation system in future and also designed LIM for electromagnetic aircraft launch system. Jean Thomas [19] proposed PSO to solve nonlinear and non-convex optimization problems by neglecting output and states constraints. Hasan Ravanji [20] investigated design of a ladder-type single-sided linear induction motor for various electrical machine tool applications. Hsin-Han Chiang [21] developed System on programmable chip (SoPC) based an optimized adaptive tracking control system for a LIM drive by considering unknown end effects, payload and uncertainties including the friction force. Yifei $\mathrm{Hu}$ [22] proposed preliminary Geometric analytical design to LIM drive under constrained conditions. Abdelkrim Sellam [26] proposed multi-machine approach to design Vector model based PMSM. Generally, the evolutionary algorithms like IPA, GA, PSO will suffer from selection of parameters and inertia weight. Due to this they take large number of iterations and more convergence time. The proposed method overcomes the short comings of above algorithms.

In this paper, section 2 presents equivalent circuit of LIM, section 3 explains Identification of LIM parameters using Taguchi method, section 4 analyze dynamical model of LIM, section 5 presents analysis of LIM using FEM based on TA and section 6 concludes the computer simulations results.

\section{Equivalent Circuit model of LIM}

Figure 1 shows the architecture of the LIM. LIM primary side is made-up of steel cores and secondary side made-up of the combination of aluminum sheets (nonmagnetic conductors) and back irons (magnetic conductors). An approximate equivalent circuit is used for the design analysis of desired speed flat LIM [25]. For finding the resistance of conducting sheet of secondary, the concept of surface resistivity is useful. Figure. 2 shows the approximate equivalent circuit of a LIM.

$$
\begin{aligned}
& \mathrm{R}_{s}=\frac{\rho_{\mathrm{W}} \mathrm{l}_{\mathrm{W}}}{\mathrm{A}_{w t}} \\
& \mathrm{X}_{\mathrm{s}}=\frac{2 \mu_{0} \pi\left[\left(\lambda_{\mathrm{s}}\left(1+\frac{3}{\mathrm{p}}\right)+\lambda_{\mathrm{d}}\right) \frac{\mathrm{W}_{\mathrm{s}}}{\mathrm{q}}+\lambda_{\mathrm{e}} \mathrm{I}{ }_{\mathrm{ce}}\right] \mathrm{N}^{2}}{\mathrm{p}} \\
& \mathrm{X}_{\mathrm{m}}=\frac{24 \mu_{0} \pi \mathrm{f}_{\mathrm{se}_{\mathrm{W}}} \mathrm{N}_{1}^{2} \tau}{\pi^{2} \mathrm{pg}_{\mathrm{e}}} \\
& \mathrm{R}_{r}=\frac{\mathrm{X}_{\mathrm{m}}}{\mathrm{G}}
\end{aligned}
$$




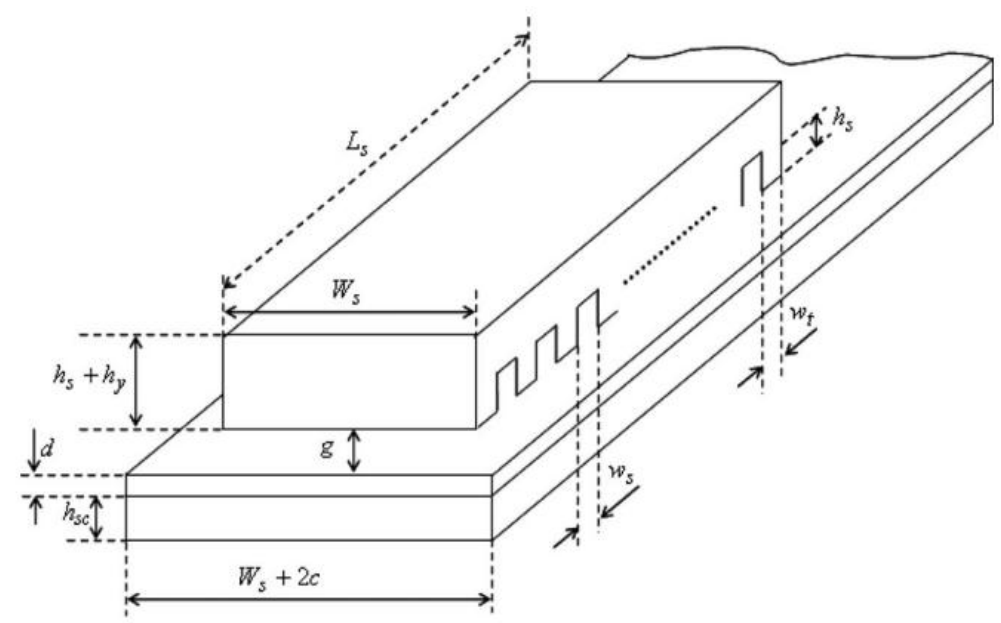

Figure 1. Architecture of a single sided LIM.

$$
\begin{gathered}
\mathrm{G}=\frac{2 \mu_{0} \mathrm{f}_{1} \tau^{2}}{\left(\frac{\rho_{\mathrm{r}}}{\mathrm{d}}\right) \mathrm{g}_{\mathrm{e}}} \\
F_{S}=\frac{m I_{1}^{2} R_{r}}{\left[\frac{1}{(s G)^{2}}+1\right] s V_{s}} \\
\eta=\frac{F_{S} 2 \tau f_{1}(1-s)}{F_{S} 2 \tau f_{1}+3 I^{2} R_{1}} \\
\cos \phi=\frac{F_{S} 2 \tau f_{1}+3 I^{2} R_{1}}{3 V I}
\end{gathered}
$$

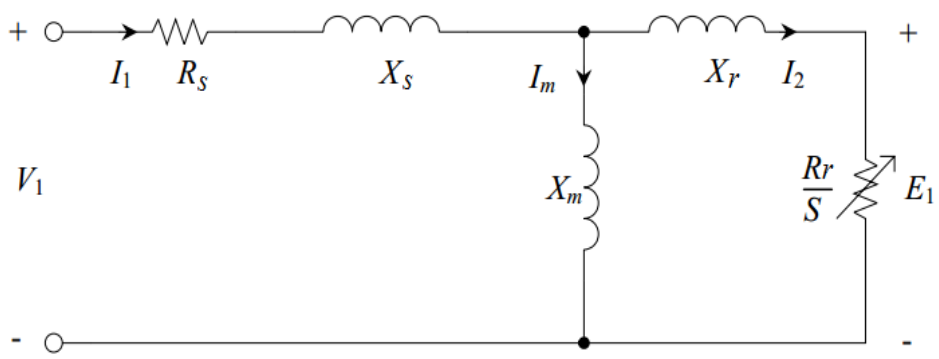

Figure 2. Equivalent circuit of a LIM.

Where, $\rho_{\mathrm{w}}$ is the copper wire volume resistivity used in the stator winding, $1_{\mathrm{w}}$ is the length of the copper wire per phase, $A_{w t}$ is the cross sectional area of the wire, $\lambda_{s}$ is the slot permeance, $\lambda_{d}$ differential permeance, $k_{p}$ is the pitch factor, $\lambda_{\mathrm{e}}$ end connection permeance, $k_{w}$ is the winding 
factor, $\mathrm{g}_{\mathrm{e}}$ is the equivalent air gap, $w_{s e}$ is the equivalent stator width, $\rho_{\mathrm{r}}$ is the volume resistivity of the rotor conductor outer layer and $f_{l}$ is primary frequency.

\section{Identification of LIM parameters using TAGUCHI}

In order to improve efficiency and power factor of LIM, the effective design parameters should be known. In this section design parameters are chosen as maximum thrust slip $(s)$, pole pitch $(\tau)$, aluminium thickness $(\mathrm{d})$ and primary current density $(J)$. The design variables and constraints are as listed in Table 1 . To obtain required efficiency and power factor the objective function is defined as eq. (9)

$$
F_{\mathrm{n}}\left(x_{1}, x_{2}, x_{3}, x_{4}\right)=\eta(s, \tau, \mathrm{d}, J)^{\mathrm{k} 1} \cdot p_{f}(s, \tau, \mathrm{d}, J)^{\mathrm{k} 2}
$$

As seen in Eq. (9), the power factor and the efficiency are adjusted by power coefficients to meet required performance. Minimization of $F_{n}$ fulfils both objectives of the optimization. When power factor is more important, choose $\mathrm{k}_{1}=0, \mathrm{k}_{2}=1$ and when efficiency is more important than power factor, choose $\mathrm{k}_{1}=1, \mathrm{k}_{2}=0$. By considering $\mathrm{k}_{1}=\mathrm{k}_{2}=1$, optimized simultaneously to meet desired efficiency and power factor.

Table 1. Design variables of optimization problem

\begin{tabular}{|l|l|l|l|}
\hline Parameter & units & Max. & Min. \\
\hline Maximum thrust slip $(s)$ & --- & 0.1 & 0.3 \\
\hline Pole Pitch $(\tau)$ & $M m$ & 40 & 60 \\
\hline Aluminium thickness $(d)$ & $m m$ & 3 & 6 \\
\hline $\begin{array}{l}\text { Primary current Density } \\
(J)\end{array}$ & $\mathrm{A} / m^{2} m^{2}$ & 1 & 3 \\
\hline Efficiency $(\eta)$ & --- & 0.7 & -- \\
\hline Power Factor $(p . f)$. & --- & 0.7 & -- \\
\hline
\end{tabular}

Taguchi Method is an optimization algorithm developed by Wei Chung Weng, et.al., 2007 [23]. Taguchi method is an advanced novel approach based on the orthogonal array (OA) concept and that can rapidly optimize the varying factors to meet desired specifications with degrees of freedom. Since TA is an effective analysis technique to find out the dominant control factor and its associated level, which significantly affect the experimental results. Figure 3 shows the flow chart of TA. Steps involved in the process of TA are as follows:

Step 1: Identify $s, \tau, \mathrm{d}, J$ parameters affecting the system operation.

Step 2: Initialize the Orthogonal Array (OA) table according to the parameters.

Step 3: Define input parameters data from OA

Step 4: Define objective functions i.e., fitness functions

$F_{1}=\eta(s, \tau, \mathrm{d}, J)=\eta\left(x_{1}, x_{2}, x_{3}, x_{4}\right)$ and $F_{2}=p f(s, \tau, \mathrm{d}, J)=p f\left(x_{1}, x_{2}, x_{3}, x_{4}\right)$

Step 5: Obtain the Matrix experiment and define its range.

$$
\begin{gathered}
\left(N_{i j}\right)_{\text {higher }}=\frac{x_{i j}-\left(x_{i j}\right)_{\min }}{\left(x_{i j}\right)_{\max }-\left(x_{i j}\right)_{\min }} \\
\left(N_{i j}\right)_{\text {lowerr }}=\frac{\left(x_{i j}\right)_{\max }-x_{i j}}{\left(x_{i j}\right)_{\max }-\left(x_{i j}\right)_{\min }}
\end{gathered}
$$

Where, $\mathrm{N}_{i j}=$ Normalized values; $\left(x_{i j}\right)_{\max }=$ maximum value of response parameter; $\left(x_{i j}\right)_{\min }=$ minimum value of response parameter and $x_{i j}=$ Value of response of $\mathrm{i}^{\text {th }}$ column and $\mathrm{j}^{\text {th }}$ row of design matrix.

Step 6: Convert the fitness value in to SN Ratio using best experiment in $\mathrm{db}$ 


$$
\text { i.e., } \left.\mathcal{F}_{d b}=-20 \log _{10} \text { (fitness function }\right)
$$

Step 7: Check the stopping criteria and convergence, if it is satisfied goto step 11.

Step 8: Create variance response table by averaging the $\mathrm{SN}$ ratios for each parameter and each level

$$
m=\frac{1}{n} \sum_{j=1}^{n} F_{d b}
$$

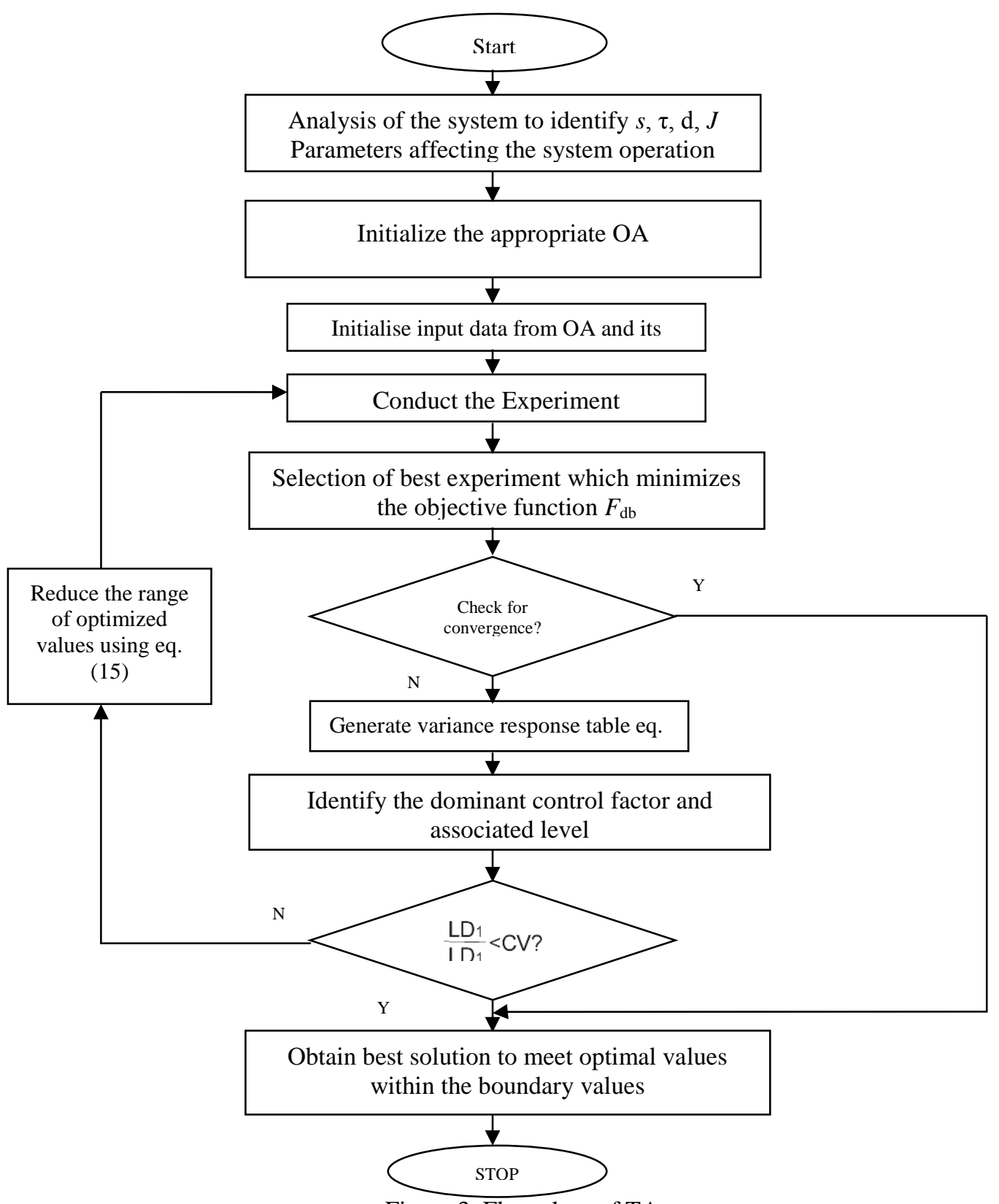

Figure 3 . Flow chart of TA. 
Step 9: Identify the dominant control factor and associated level according to the variance table and Conduct Confirmation Experiment.

Step 10: Check the stopping criteria and convergence, if it is not satisfied reduce the range of optimized values and then goto step 5 .

$$
R R(i)=\frac{\text { Level Difference in }(i+1)^{\text {th }} \text { iteration }}{1^{\text {st }} \text { Level Difference }}=\frac{L D_{i+1}}{L D_{1}}
$$

Step 11: Find the best solution to obtain the optimal values within the constraints.

Step 12: Stop

Table 2. Comparison of various optimization results

\begin{tabular}{|c|c|c|c|c|c|c|c|}
\hline Method & $s$ & $\tau$ & $\mathrm{d}$ & $J$ & $\eta$ & $p . f$. & $\mathrm{t}_{\mathrm{c}}$ \\
\hline $\begin{array}{c}\text { IPA } \\
{[13]}\end{array}$ & 0.13 & 48.2463 & 4.9955 & 2.0154 & 0.658 & 0.551 & 14 \\
\hline $\begin{array}{c}\text { GA } \\
{[16]}\end{array}$ & 0.1495 & 48.0000 & 4.8000 & 2.1000 & 0.67959 & 0.608 & 8.165 \\
\hline $\begin{array}{c}\text { PSO } \\
{[19]}\end{array}$ & 0.1495 & 48.0671 & 4.8019 & 2.1000 & 0.68968 & 0.619 & 4.239 \\
\hline TA & 0.1032 & 40.0 & 5.1 & 1.8000 & 0.7 & 0.6989 & 1.473 \\
\hline
\end{tabular}

Table 2 shows, the comparison of optimized motor dimensions using Interior Point algorithm (IPA), genetic algorithm (GA), Particle Swarm Optimization (PSO) and Taguchi Algorithm (TA). From the table it is observed that the proposed method gives better optimum design parameters and hence improves the power factor and efficiency with less convergence time compared to other methods.

\section{Dynamic Modeling of LIM}

The dynamic model of the LIM can be expressed in the synchronously rotating frame. The dynamic model of the 3-phase star connected LIM can be described by the following differential equations [25].

$$
\begin{aligned}
& \frac{d i_{d s}}{d t}=\frac{1}{\sigma L_{s}}\left(-\left(R_{S}+\left(\frac{L_{m}}{L_{r}}\right)^{2} R_{r}\right) i_{d s}+\sigma L_{S} \frac{\pi}{\tau} v_{e} i_{q s}+\frac{L_{m} R_{r}}{L_{r}^{2}} \phi_{d r}+\frac{P L_{m} \pi}{L_{r} \tau} \phi_{q r} v_{r}+V_{d s}\right) \\
& \frac{d i_{q s}}{d t}=\frac{1}{\sigma L_{s}}\left(-\sigma L_{s} \frac{\pi}{\tau} v_{e} i_{d s}-\left(R_{s}+\left(\frac{L_{m}}{L_{r}}\right)^{2} R_{r}\right) i_{q s}-\frac{P L_{m} \pi}{L_{r} \tau} \phi_{d r} v_{r}+\frac{L_{m} R_{r}}{L_{r}^{2}} \phi_{q r}+V_{q s}\right) \\
& \frac{d \phi_{d r}}{d t}=\frac{L_{m} R_{r}}{L_{r}} i_{d s}-\frac{R_{r}}{L_{r}} \phi_{d r}+\left(\frac{\pi}{\tau} v_{e}-P \frac{\pi}{\tau} v_{r}\right) \phi_{q r} \\
& \frac{d \phi_{q r}}{d t}=\frac{L_{m} R_{r}}{L_{r}} i_{q s}-\left(\frac{\pi}{\tau} v_{e}-P \frac{\pi}{\tau} v_{r}\right) \phi_{d r}-\frac{R_{r}}{L_{r}} \phi_{q r} \\
& F_{e}=K_{f}\left(\phi_{d r} i_{q s}-\phi_{q r} i_{d s}\right)=M v_{r}+D v_{r}+F_{L}
\end{aligned}
$$

Where $v_{\mathrm{r}}$ is the mover linear velocity; $\tau$ is the pole pitch; $P$ is the number of pole pairs; $\varphi_{\mathrm{dr}}$ and $\varphi_{\mathrm{qr}}$ be $\mathrm{d}$-axis and q-axis secondary flux; $\mathrm{i}_{\mathrm{ds}}$ and $\mathrm{i}_{\mathrm{qs}}$ be $\mathrm{d}$-axis and q-axis primary current; $\mathrm{V}_{\mathrm{ds}}$ and $\mathrm{V}_{\mathrm{qs}}$ are $\mathrm{d}$-axis and $\mathrm{q}$-axis primary voltage; External force disturbance be $\mathrm{F}_{\mathrm{L}}$, electromagnetic force be $\mathrm{F}_{\mathrm{e}}, \mathrm{M}$ be the total mass of the moving element and $\mathrm{D}$ be the viscous friction coefficient. 5. Finite Element Analysis for LIM using TA 
The validity of the design optimizations greatly depends on the accuracy of the model such as saturation, nonlinearity of materials and etc. Thus, in this section 2-D time stepping FEMM are employed to evaluate the new equivalent circuit LIM model. The optimal designed parameters of LIM are graphically analyzed with respect to flux density distribution, magnetic flux density and eddy current density using finite element analysis. The equation of magnetic field with respect to eddy currents can be written as

$$
\begin{aligned}
& \nabla \times(v \nabla \times A)=J_{o}+J \\
& J_{e}=-\sigma\left(\frac{\partial A}{\partial t}+\operatorname{grad} \phi\right) \\
& \nabla \bullet J_{o}=0
\end{aligned}
$$

In FEM, using time-stepping analysis relative moment is measured. The force is produced by a linearly moving magnetic field acting on conductors in the fields are calculated using local virtual work method. Figure. 11 and Figure. 12 shows, the flux density distribution and graphical representation of flux lines in the analyzed LIM, respectively. Figure. 13 and Figure. 14 shows, comparison of flux density and eddy current density $\left(J_{e}\right)$ of LIM.

\section{Simulations Results and discussions}

The novel optimization TA has been applied to meet required efficiency and power factor in the design of a Linear Induction Motor are shown in Figures. 6 to 10 and FEMM results of LIM has been shown in Figures. 11 to 14.

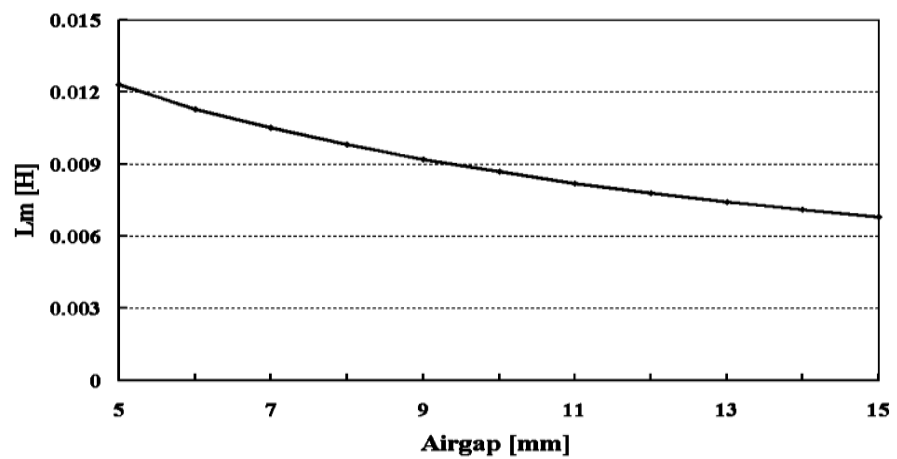

Figure 4. Magnetizing inductance according to variation of the airgap length

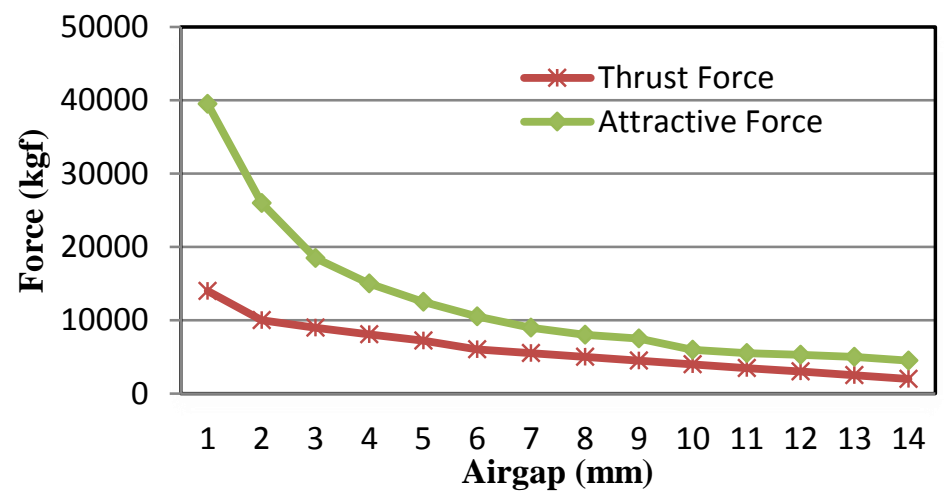

Figure 5. Forces according to variation of the airgap length 
Ch. V. N. Raja, et al.

From Figure 4 and Figure 5, increase the airgap, increases the leakage flux and reluctance of the magnetic circuit and decreases the magnetizing inductance, attractive and repulsive forces.

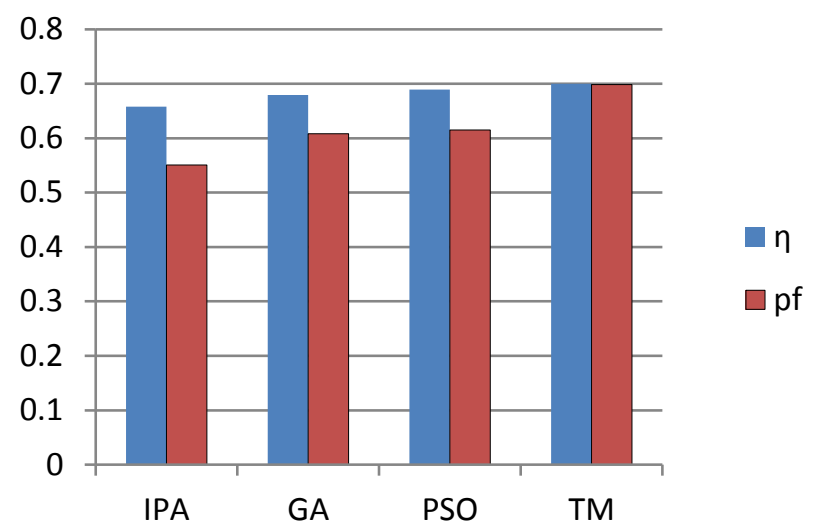

Figure 6. Comparison of efficiency and power factor between various optimization methods

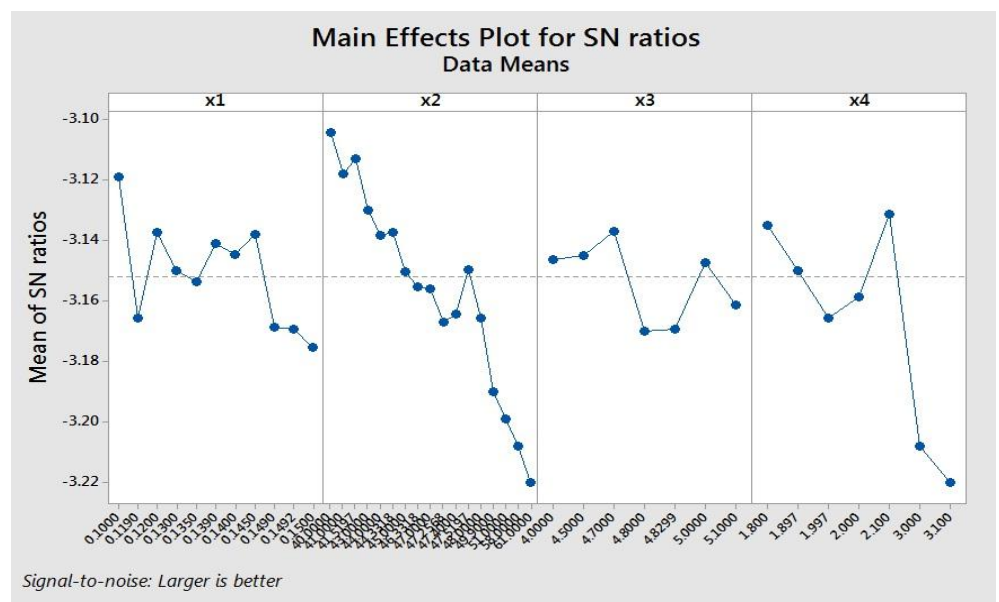

Figure. 7. Mean effects plot for SN Ratio using Taguchi optimization

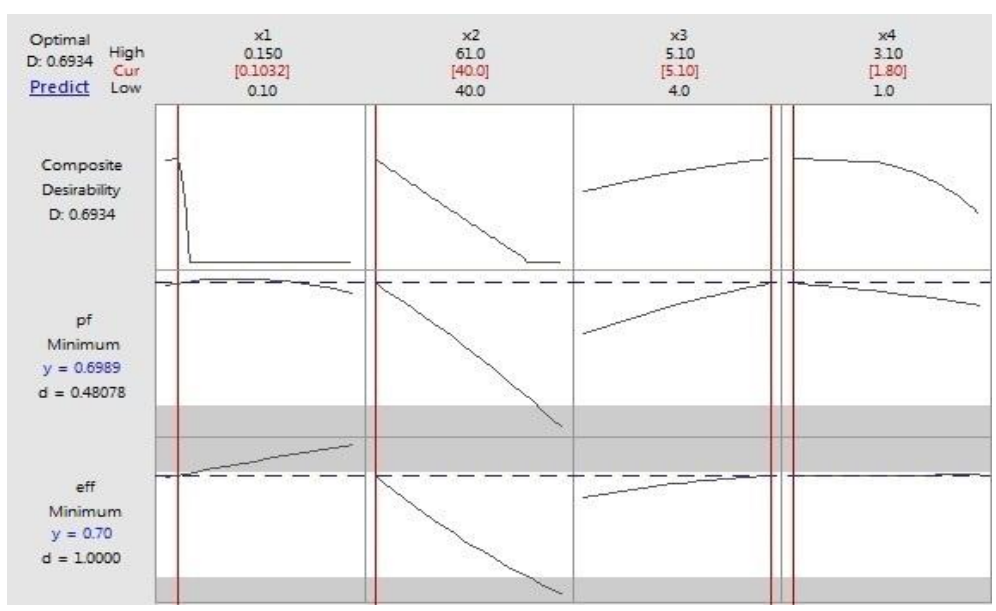

Figure. 8. Taguchi optimization plot 


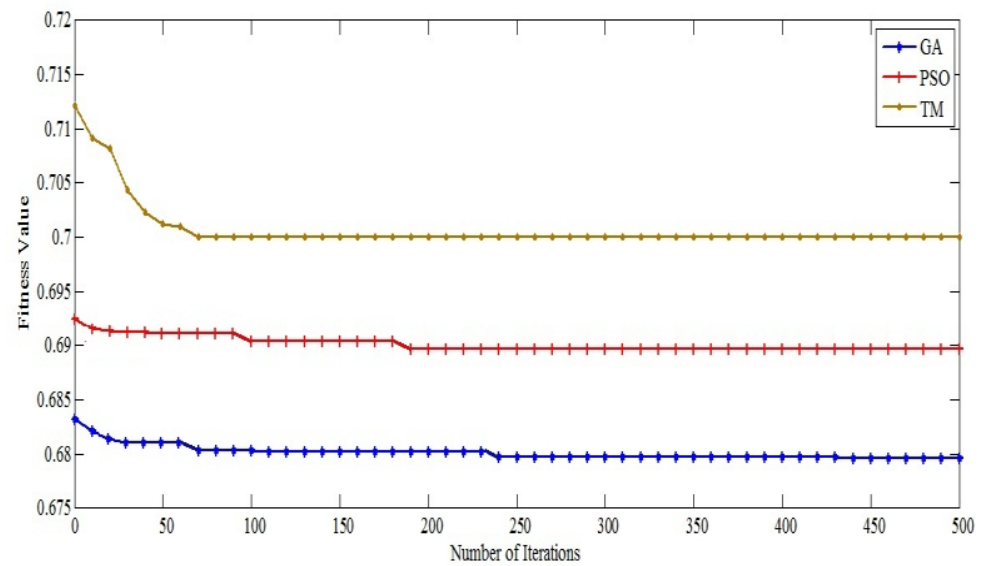

Figure 9. Comparison Fitness functions of different optimization methods

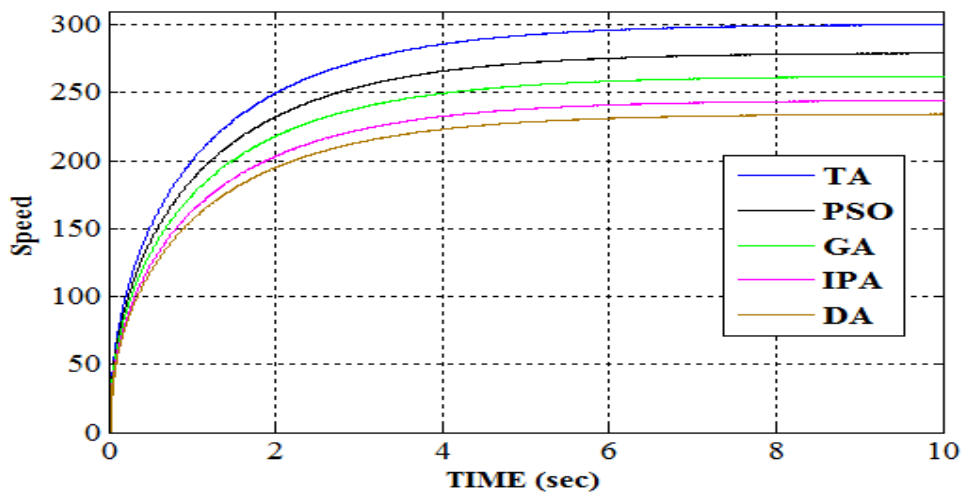

Figure. 10. Comparison of open loop LIM speed for different OPTIMIZATION METHODS
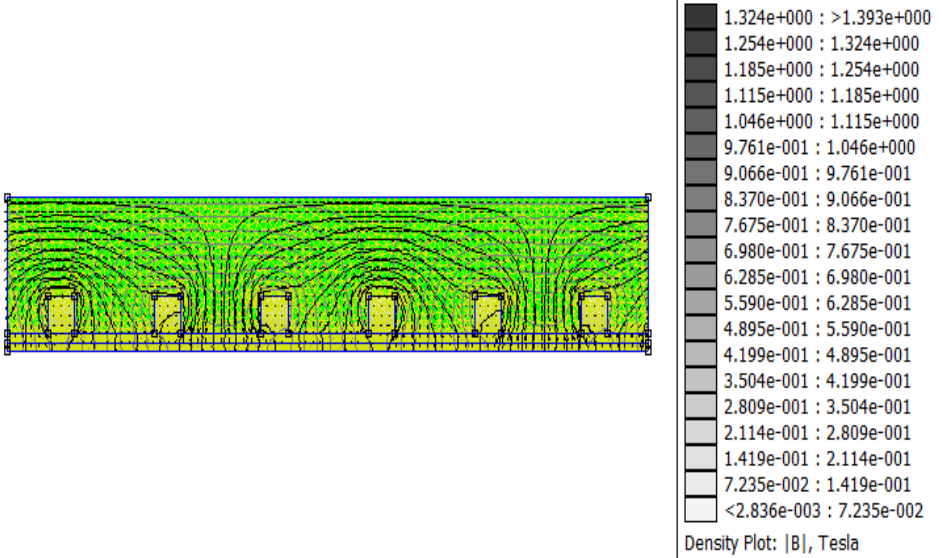

Figure 11. Flux density distribution in the LIM using Taguchi 
Ch. V. N. Raja, et al.

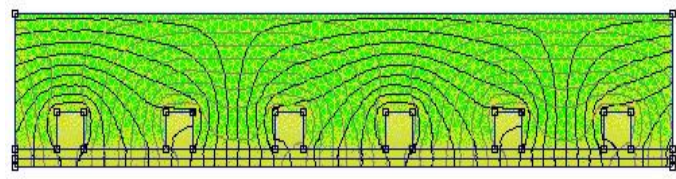

$1.393 e+000:>1.467 e+000$ $1.320 \mathrm{e}+000: 1.393 \mathrm{e}+000$ $1.247 \mathrm{e}+000: 1.320 \mathrm{e}+000$

$1.174 \mathrm{e}+000: 1.247 \mathrm{e}+000$

$1.101 \mathrm{e}+000: 1.174 \mathrm{e}+000$

$1.028 \mathrm{e}+000: 1.101 \mathrm{e}+000$

$9.543 \mathrm{e}-001: 1.028 \mathrm{e}+000$

$8.811 \mathrm{e}-001: 9.543 \mathrm{e}-001$

$8.079 \mathrm{e}-001: 8.811 \mathrm{e}-001$

$7.348 \mathrm{e}-001: 8.079 \mathrm{e}-001$

$6.616 \mathrm{e}-001: 7.348 \mathrm{e}-001$

$5.884 \mathrm{e}-001: 6.616 \mathrm{e}-001$

$5.152 \mathrm{e}-001: 5.884 \mathrm{e}-001$

$4.420 \mathrm{e}-001: 5.152 \mathrm{e}-001$

$3.688 \mathrm{e}-001: 4.420 \mathrm{e}-001$

$2.956 \mathrm{e}-001: 3.688 \mathrm{e}-001$

$2.224 \mathrm{e}-001: 2.956 \mathrm{e}-001$

$1.492 \mathrm{e}-001: 2.224 \mathrm{e}-001$

$7.604 \mathrm{e}-002: 1.492 \mathrm{e}-001$

$<2.852 \mathrm{e}-003: 7.604 \mathrm{e}-002$

Density Plot: $|\mathrm{B}|$, Tesla

Figure 12. Flux density distribution in the LIM using PSO
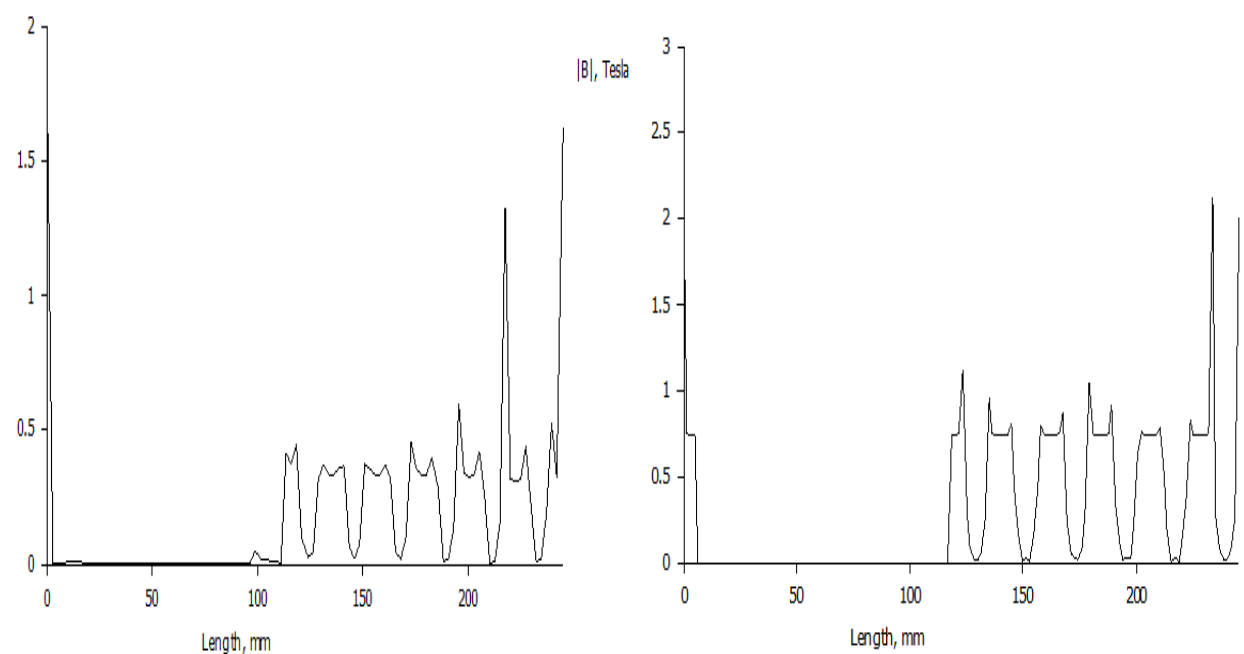

Figure 13. Magnitude of flux density LIM (Taguchi and PSO) using FEM
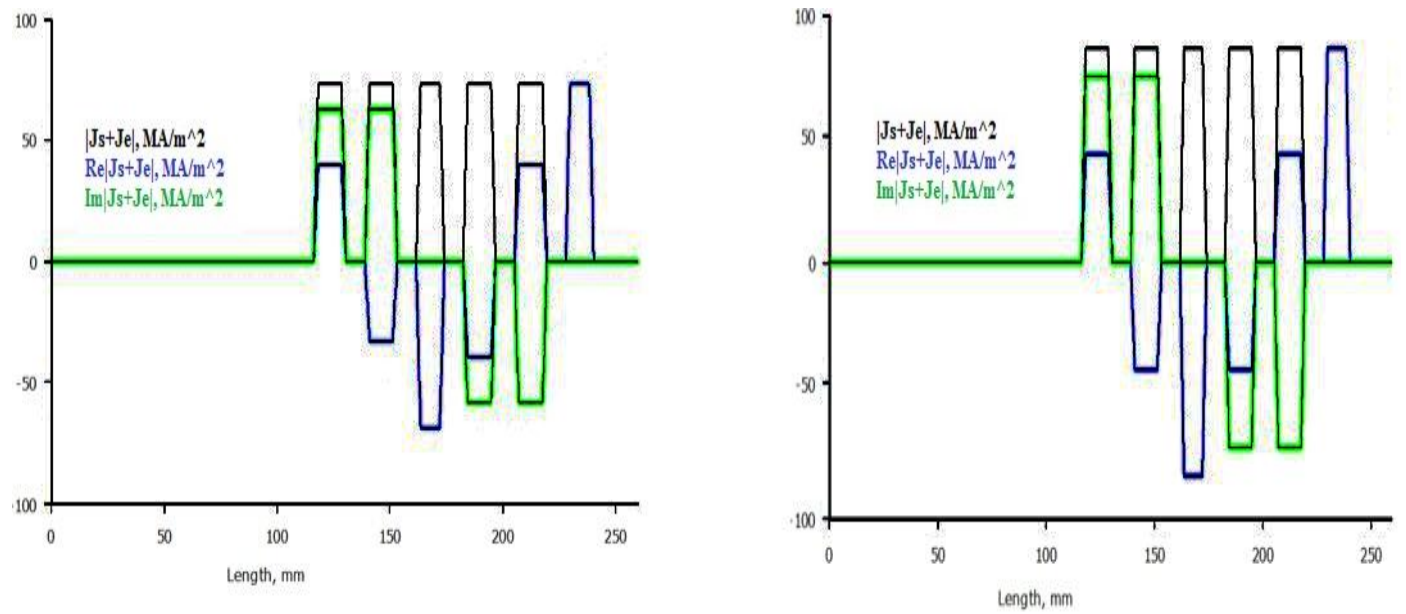

Figure. 14. Eddy current density $\left(J_{e}\right)$ of LIM (Taguchi and PSO) using FEM 
From Figure. 11 and Figure. 12, the flux lines are localized in front of the LIM and expand behind the LIM due to velocity effect. Figure. 13 and Figure. 14 shows, comparison of flux density and eddy current density $\left(J_{e}\right)$ of LIM using FEM.

\section{Conclusions}

In this paper, multi-objective TA optimization method is proposed for optimized dimensions of a linear induction motor to meet the required efficiency and power factor. From the characteristics of proposed method it is observed that less air-gap have a better thrust, efficiency and less excitation current. The effect of parameters of the LIM on efficiency and power factor is observed in SN Ratio plot. Using FEMM with TA based LIM the flux and eddy current density are less when compared to FEMM with PSO based LIM. Based on the results, it can be concluded that design of LIM using TA optimization technique takes less converging time, less number of iterations to achieve desired power factor, efficiency and high speed.

\section{References}

[1]. I. Boldea., S. A. Nasar S. A. Linear Motion Electromagnetic System, New Jersy, John Wiley \& Sons Inc., 1995.

[2]. Dr. Luciano Martins Neto., Euler B. Dos Santos, Jose R Camncho, "Linear Induction Motor parameter determination on force development applications," Proceedings of the IEEE conf. on Power Eng. Society Winter Meeting, Espoo, Jan. 2000, pp. 354-358.

[3]. K. Davey, "Pulsed linear induction motors in Maglev applications," IEEE Transactions on Magnetics, Vol. 36, no.5, pp. 3703 - 3705, 2000.

[4]. R. Hofmann, A. Binder, R. Pfeiffer, "Investigations on a linear induction machine for railway applications," IEEE conf. On Electric Machines and Drives, Cambridge, June 2001, pp. 20-22.

[5]. K. Fujisaki, "Linear induction motor application to thin steel plate," IEEE conf. on Magnetics, Netherlands, May 2002, pp. 04-05.

[6]. J.R.Wells, P.L. Chapman, "Development and application of a linear induction machine for instructional laboratory use," IEEE conf. On Power Electronics Specialists, USA, Sept. 2002, pp. $479-482$.

[7]. Junha Kim, Bon Gwan Gu, Gubae Kang, K. Nam, "Attractive force reducing strategy of LIM for PRT systems," IEEE conf. On Electric Machines and Drives, South korea, June, 2003, pp. 1832 - 1836.

[8]. H. Amirkhani, A. Shoulaie, "Online control of thrust and flux in linear induction motors," IEE Proceedings - Electric Power Applications, Vol. 150, no.5, pp. 515 - 520, 2003.

[9]. Haruo Noma, Shunsuke Yoshida, Yasuyuki Yanagida, Nobuji Tetsutani, "The Proactive Desk: A New Haptic Display System for a Digital Desk Using a 2-DOF Linear Induction Motor," IEEE Transactions on Presence, Vol. 13, no.2, pp. 146 - 163, 2004.

[10]. T.C.O. Connell, P.T. Krein, "Development of a first-principles design method for electromechanical systems a linear induction machine," IEEE conf. On Electric Machines and Drives, San Antonio, May 2005, pp. $474-480$.

[11]. F.L. Jianqiang Liu, Zhongping Yang, Q.Z. Trillion, "Optimal Efficiency Control of Linear Induction Motor Drive for Linear Metro," IEEE conf. On Electric Industrial Electronics and Applications, Harbin, May 2007, pp. 1981 - 1985.

[12]. Renato Crivellari Creppe, Jose Alfredo Covolan Ulson, Jose Francisco Rodrigues, "Influence of Design Parameters on Linear Induction Motor End Effect," IEEE Trans. on Energy Conversion, Vol. 23, no.2, pp. 358-362, 2008.

[13]. Nilanjan Chakraborty, Jufeng Peng, Srinivas Akella, John E. Mitchell, "Proximity Queries Between Convex Objects: An Interior Point Approach for Implicit Surfaces," IEEE Trans. on Robotics, Vol. 24, no. 1, pp. 211 -220, 2008.

[14]. V.P. Sakthivel, R. Bhuvaneswari, S. Subramanian, "Multi-objective parameter estimation of induction motor using particle swarm optimization," Engineering Applications of Artificial Intelligence, Vol. 23, no. 3, pp. 302 - 312, 2010. 
[15]. Ai-min Liu, Hong-kui Zhang, Guang Yang, Xin Lin, "Research and application of multiobjective particle swarm optimization in linear induction motor operating mechanism," IEEE conf. on Electric Power Equipment - Switching Technology, Xi'an, Oct. 2011, pp. $291-295$.

[16]. A. Shiri, A. Shoulaie, "Design Optimization and Analysis of Single-Sided Linear Induction Motor, Considering All Phenomena," IEEE Transactions on Energy Conversion, Vol. 27,no.3, pp. $516-525,2012$.

[17]. G. Lopez Victor, N. Sanchez Edgar, Y. Alanis Alma, "PSO neural inverse optimal control for a linear induction motor," IEEE conf. on Evolutionary Computation, Cancun, June 2013, pp. 1976 - 1982.

[18]. H. Yaghoubi, "The most important Maglev application," Journal of Eng., Vol. 20, no. 13, pp. 1-9, 2013.

[19]. Jean Thomas, "Particle swarm optimization based model predictive control for constrained nonlinear systems," IEEE conf. on Informatics in Control, Automation and Robotics, Austria, Sept. 2014, pp. 397 - 403.

[20]. R. Mohammad Hasan, G. Zahra Nasiri, "Design Optimization of a Ladder Secondary Single-Sided Linear Induction Motor for Improved Performance, ” IEEE Trans. on Energy Conversion, Vol. 30, no.4, pp. 1595 - 1603, 2015.

[21]. Hsin-Han Chiang, Kou-Cheng Hsu, I-Hsum Li, "Optimized Adaptive Motion control through an SoPC Implementation for Linear Induction Motor Drives," IEEE Trans. on mechatronics, Vol. 20, no. 1, pp. 348-360, 2015.

[22]. Yifei Hu, Alija Cosic, Stefan Ostlund, Hui Zhang, "Design and Optimization Procedure of a Single-Sided Linear Induction Motor Applied to an Articulated Funiculator," IEEE conf. on Power Electronics and Motion Control, China, May 2016, pp. 976 - 982.

[23]. W.C. Weng, F. Yang, A. Elsherbeni, "Linear antenna array synthesis using Taguchi's method: A novel optimization technique in electromagnetic," IEEE Trans. Antennas Propag., Vol. 55, no. 3, pp. 723-730, 2007.

[24]. A. Hassanpour Isfahani, B.M. Ebrahimi, H. Lesani, "Design optimization of a low speed single-sided linear induction motor for improved efficiency and power factor," IEEE Trans Magn. Vol. 44, no.2, pp. 266-272, 2008.

[25]. Ch. V N Raja, K. Rama Sudha, "Design, Analysis of Linear Induction Motor based on Harmony Search Algorithm and Finite Element Method, "Journal of Engineering Science and Technology Review, Vol. 9, no.6, pp. 189-195, 2016.

[26].L. Abdelkrim Sellam, D. Boubakeur, B. Boubakeur, Mustapha Djouhri, (2013). “A Vectorial modeling for the Permanent Magnet Synchronous Machine (polyphase) based on multimachine approach," International Journal on Electrical Engineering and Informatics, Vol. 5, no. 1, pp. 67-80, 2013. 


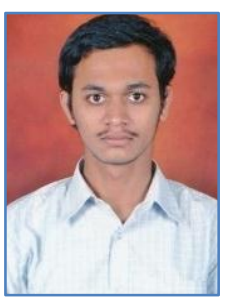

Ch. V. N. Raja received his B.E in Electrical and Electronics Engineering from A.U. Andhra Pradesh, India, in 2008 and M.E in Control Systems from Andhra University, Andhra Pradesh, India, in 2010. He is currently working towards his $\mathrm{PhD}$ degree at Andhra University, Visakhapatnam, India. He is currently working as Assistant Professor in the department of Electrical and Electronics Engineering in ANITS Engineering College, Andhra Pradesh, India. His research interests include neural networks, fuzzy logic, Control systems applications to Electrical Machines and Optimization Techniques.

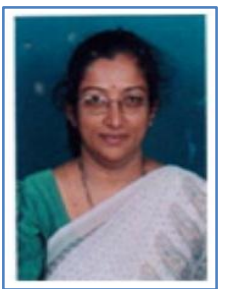

K. Rama Sudha received her BE in Electrical and Electronics Engineering and ME in Power Systems from Andhra University, Visakhapatnam in 1991 and 1994. She was awarded her Doctorate in Electrical Engineering by Andhra University in 2006. During 1994-2006, she worked with GITAM Engineering and presently she is working as Professor in the Department of Electrical Engineering, Andhra University college of Engineering for women, Andhra University, Visakhapatnam, India. 